\title{
A Data Analysis of D-Dimer \& Interleukin-6 (IL-6) Test for Covid Patient
}

Batabyal $\mathrm{B}^{1 *}$, Roy $\mathbf{P}^{2}$ and Das $\mathrm{A}^{3}$

${ }^{1}$ Microbiologist, Serum Analysis Centre Pvt. Ltd, Howrah, West Bengal, India

${ }^{2}$ Department of Microbiology, Serum Analysis Centre Pvt. Ltd, Howrah, West Bengal, India

${ }^{3}$ Department of Microbiology, Techno India University, West Bengal, India

*Corresponding author: Biswajit Batabyal, Microbiologist, Serum Analysis Centre Pvt. Ltd, Howrah, West Bengal, India

Received: May 01, 2021; Accepted: J une 19, 2021 Published: June 26, 2021

\begin{abstract}
Various biomarkers, especially inflammatory markers like C-reactive protein (CRP), ferritin, fibrinogen, D-dimer and Interleukin 6 (IL-6) are associated with Covid-19 progression. Thrombosis prophylaxis with low molecular weight heparin has shown beneficial results in preventing coagulopathy a reducing risk of mortality due to thrombotic events. The COVID-19 patients highlighting the role of D-dimer, and Interleukin-6 (IL-6).
\end{abstract}

During plasma coagulation soluble fibrin is generated by the influence of thrombin on fibrinogen. The soluble fibrin is crosslinked to the vessel walls by factor XIIla. When splitting this cross linked fibrin, characteristic products called D-dimers are released. Increased D-dimer concentrations are found in thrombotic diseases and microthrombotic events (e.g. in case of disseminated intravascular coagulation, DIC). D-dimer determination is mainly used to exclude deep vein thrombosis of the leg and pulmonary embolism. D-Dimer levels rise during pregnancy and high levels are associated with complications. D-dimer is a fibrin degradation product that is often used to measure and assess clot formation. Amid the COVID-19 pandemic, elevated D-dimer levels have been associated with disease severity and mortality trends.

Interleukin-6 (IL-6) is a pro-inflammatory cytokine secreted by T cells and macrophages to stimulate immune response to trauma, especially burns or other tissue damage leading to inflammation. IL-6 is also secreted by macrophages in response to specific microbial molecules, referred to as Pathogen Associated Molecular Patterns (PAMPs), which trigger the innate immune response and initiate inflammatory cytokine production. IL- 6 is one of the most important mediators of fever and of the acute phase response. IL-6 is also called a "myokine", a cytokine produced from muscle that increases in response to muscle contraction. Additionally, osteoblasts secrete IL-6 to stimulate osteoclast formation.

The detection and control of pro-inflammatory response is crucial in the early stages of viral infection. COVID-19 is an emerging viral disease of global concern and optimal treatment has yet to be determined. Unknown response of treatment of COVID-19 is important during patient monitoring. IL-6 is one of the key cytokines after activated macrophages.

Here we will present a laboratory data analysis of COVID-19 patients in different age group highlighting the role of positivity D-dimer and interleukin-6 (IL-6).

Keywords: Covid-19; D-dimer; Cytokine; Cytokine storm; IL-6; Mortality trends

\section{Introduction}

Various biomarkers, mainly inflammatory markers like C-reactive protein (CRP), ferritin, fibrinogen, D-dimer and Interleukin 6 (IL-6) are associated with Covid-19 progression. Thrombosis prophylaxis with low molecular weight heparin has shown beneficial results in preventing coagulopathy a reducing risk of mortality due to thrombotic events. The COVID-19 patients highlighting the role of D-dimer, and interleukin-6 (IL-6).

During blood coagulation, fibrinogen is converted to fibrin by the activation of thrombin. The resulting fibrin monomers polymerize to form a soluble gel of non-cross-linked fibrin. This fibrin gel is then converted to cross-linked fibrin by thrombin activated Factor XIII to form an insoluble fibrin clot. Production of plasmin, the major clotlysing enzyme, is triggered when a fibrin clot is formed. Fibrinogen and fibrin are both cleaved by the fibrinolytic enzyme plasmin to yield degradation products, but only degradation products from cross-linked fibrin contain D-Dimer. Therefore, crosslinked fibrin degradation products (XL-FDP) are a specific marker of fibrinolysis.

Deep-vein thrombosis is a common condition, with a lifetime cumulative incidence of 2 to 5 percent. Untreated deep-vein thrombosis can result in pulmonary embolism, a potentially fatal outcome. Anticoagulant therapy reduces both morbidity and mortality 
from venous thromboembolism, and early diagnosis is therefore important. Accurate diagnosis of deep-vein thrombosis minimizes the risk of thromboembolic complications and averts the exposure of patients without thrombosis to the risks of anticoagulant therapy. D-Dimer is a marker of endogenous fibrinolysis and should therefore be detectable in patients with deep-vein thrombosis. In recent years, an increasing number of studies have shown the D-Dimer assay has a high negative predictive value and D-Dimer is a sensitive but nonspecific marker of deep-vein thrombosis. Negative D-Dimer can exclude deep-vein thrombosis and pulmonary embolism.

Fibrin Degradation Products (FbDP) are a highly heterogeneous group of soluble fragments that appear in the circulation as a result of two simultaneous physiological processes: 1) - Coagulation, resulting in the conversion of soluble fibrinogen into insoluble stabilized fibrin by the enzymes thrombin and factor XIIIa, - Fibrinolysis, resulting in the dissolution of the fibrin clot by the enzyme plasmin. The D-dimer fragment is the terminal product of this process; 2) Although FbDP's vary in size, they are characterized by the presence of one or more D-dimer epitopes [1,2]. Therefore, FbDP's are collectively referred to as 'D-dimer'. Assays for $\mathrm{D}$-dimer can be performed directly in plasma by virtue of monoclonal antibodies which are able to identify fibrin-specific epitopes without cross-reactivity with fibrinogen or its degradation products [1]. D-dimer reflects the presence of stabilized fibrin and this has made this marker a useful tool in the diagnosis of Venous Thromboembolism (VTE) [3]. Quantitative D-dimer assays based on ELISA techniques have a high sensitivity for the presence of an occluding thrombus and, consequently, are particularly useful in excluding venous thromboembolic disease $[4,5]$. In conjunction with assessment of clinical pretest probability, it is possible to safely rule out the diagnosis of Deep Vein Thrombosis (DVT) and Pulmonary Embolism (PE) in suspected outpatients when the concentration of $\mathrm{D}$-dimer is below a predefined cut-off (determined by rigorous clinical studies) [5-7]. The clinical utility of D-dimer ELISA assays in the diagnostic work-up of suspected DVT or PE resides in the significant reduction in the number of imaging tests that are required with a concomitant reduction in the total cost of diagnosis $[8,9]$. D-dimer is not specific for DVT/PE and elevated levels are also observed in a variety of other conditions where activation of coagulation and fibrinolysis occurs (e.g. surgery, trauma, infection, inflammation, pregnancy, cancer); 3) This makes D-dimer less useful for exclusion of DVT or PE in hospitalized patients due to the high proportion of comorbid conditions associated with elevated D-dimer levels $(5,10)$. Under certain conditions lower than expected D-dimer results may occur giving rise to false-negatives? Therefore, it is not safe to use D-dimer for exclusion of DVT/PE in patients with high pre-test probability, long duration of DVT/PE symptoms (more than one week) or already under anticoagulant treatment $[10,11]$. Measurement of D-dimer can also be of use as an aid in diagnosing Disseminated Intravascular Coagulation (DIC) [12].

Interleukin 6 (IL-6) is an interleukin that acts as both a proinflammatory cytokine and an anti-inflammatory myokine. In humans, it is encoded by the IL6 gene [13].

In addition, osteoblasts secrete IL-6 to stimulate osteoclast formation. Smooth muscle cells in the tunica media of many blood vessels also produce IL-6 as a pro-inflammatory cytokine. IL-6's role as an anti-inflammatory myokine is mediated through its inhibitory effects on TNF-alpha and IL-1 and its activation of IL-1ra and IL-10.

There is some early evidence that IL-6 can be used as an inflammatory marker for severe COVID-19 infection with poor prognosis, in the context of the wider coronavirus pandemic [14]

Interleukin 6 (IL-6) is a pleiotropic, a-helical, 22-28 $\mathrm{kDa}$ phosphorylated and variably glycosylated cytokine that plays important roles in the acute phase reaction, inflammation, hematopoiesis, bone metabolism, and cancer progression. Mature human IL-6 is 183 Amino Acids (AA) in length and shares 39\% AA sequence identity with mouse and rat IL-6. Alternative splicing generates several isoforms with internal deletions, some of which exhibit antagonistic properties. Cells known to express IL-6 include CD8+ T cells, fibroblasts, synoviocytes, adipocytes, osteoblasts, megakaryocytes, endothelial cells (under the influence of endothelins), sympathetic neurons, cerebral cortex neurons, adrenal medulla chromaffin cells, retinal pigment cells, mast cells, keratinocytes, Langerhans cells, fetal and adult astrocytes, neutrophils, monocytes, eosinophils, colonic epithelial cells, B1 B cells and pancreatic islet beta cells. IL-6 production is generally correlated with cell activation and is normally kept in control by glucocorticoids, catecholamine's, and secondary sex steroids. Normal human circulating IL-6 is in the 1pg/ $\mathrm{mL}$ range, with slight elevations during the menstrual cycle, modest elevations in certain cancers, and large elevations after surgery.

IL-6 induces signaling through a cell surface heterodimeric receptor complex composed of a ligand binding subunit (IL-6 R alpha) and a signal transducing subunit (gp130). IL-6 binds to IL-6 Ra, triggering IL-6 Ra association with gp130 and gp130 dimerization. gp130 is also a component of the receptors for CLC, CNTF, CT-1, IL-11, IL-27, LIF, and OSM. Soluble forms of IL-6 Ra are generated by both alternative splicing and proteolytic cleavage. In a mechanism known as trans-signaling, complexes of soluble IL-6 and IL-6 Ra elicit responses from gp130-expressing cells that lack cell surface IL-6 $\mathrm{Ra}$. Trans-signaling enables a wider range of cell types to respond to IL-6, as the expression of gp130 is ubiquitous, while that of IL-6 Ra is predominantly restricted to hepatocytes, monocytes, and resting lymphocytes. Soluble splice forms of gp130 block trans-signaling from IL-6/IL-6 Ra but not from other cytokines that use gp130 as a co-receptor.

IL-6, along with TNF-a and IL-1, drives the acute inflammatory response. IL-6 is almost solely responsible for fever and the acute phase response in the liver, and it is important in the transition from acute inflammation to either acquired immunity or chronic inflammatory disease. When dysregulated, it contributes to chronic inflammation in conditions such as obesity, insulin resistance, inflammatory bowel disease, arthritis, and sepsis. IL-6 modulates bone resorption and is a major effector of inflammatory joint destruction in rheumatoid arthritis through its promotion of Th17 cell development and activity. It contributes to atherosclerotic plaque development and destabilization as well as the development of inflammation-associated carcinogenesis.

The current a laboratory data analysis in COVID-19 patients in different age group, its prevalence, and incidence. Besides, the diagnosis and pathogenesis such patients. Also, this manuscript 
highlight on the positivity role of D-dimer and interleukin-6 (IL-6) in development and investigating in COVID-19 patients in different age group.

\section{Relation between D-Dimer and Covid-19}

Several different studies have looked to measure D-dimer levels in COVID-19 patients to determine whether this biomarker could be useful in predicting patient outcomes. In one study conducted in China between January 31 and February 12, 2020, the biological characteristics of a total of 274 COVID-19 patients with a median age of 62 were analyzed.

Of the 113 patients who did not survive, it was reported that their D-dimer levels were higher at a median of $4.6 \mu \mathrm{g} / \mathrm{mL}$, whereas the surviving 161 patients had D-dimer levels that averaged at $0.6 \mu \mathrm{g} / \mathrm{mL}$.

Similar results were reported in another study conducted in China between January 1 and February 13, 2020. The D-dimer levels of 134 deceased COVID-19 patients averaged at $4.7 \mu \mathrm{g} / \mathrm{ml}$, whereas 315 patients who had survived following severe COVID-19 effects had median D-dimer levels of $1.47 \mu \mathrm{g} / \mathrm{ml}$ [15].

Although these data indicate that $\mathrm{D}$-dimer testing, in combination with the analysis of other biomarkers, can be of assistance during the treatment of COVID-19 patients, further studies must be performed to fully validate the role that $\mathrm{D}$-dimer testing can have in the decisionmaking process

\section{Relation between IL-6 and Covid-19}

IL-6 is an important cytokine with pleiotropic functions such as metabolic regulation to inflammation, auto-immunity and acutephase response. COVID-19 patients had high levels of IL- 6 that were associated with pulmonary inflammation and extensive lung damage. COVID-19 infection has an aggressive inflammatory response with a large amount of pro-inflammatory cytokines, known as the 'cytokine storm'. Acute increase in circulating levels of pro-inflammatory cytokines including IL-6, IL-1, TNF- $\alpha$ and interferon is the reason for the cytokine storm. IL- 6 may be a therapeutic target for inhibiting the cytokine storm and cytokine storm-associated organ damage.

\section{Data Analysis Study Period \& Data collection}

This was a prospective Data analysis study conducted during 1 month from $15^{\text {th }}$ April, 2021 to $14^{\text {th }}$ May, 2021 in this current situation of second wave of corona spreading in our country.

The Data analysis study of D-Dimer \& IL-6 in different age group was conducted on Covid-19 positive patients in a Reputed Referral

Table 1A: Biological Reference Interval of D-dimer <0.50ug/L (Age Group: 0-14 Years).
\begin{tabular}{|c|c|c|c|c|c|c|}
\hline $\begin{array}{c}\text { Total No. of } \\
\text { Sample }\end{array}$ & $\begin{array}{c}\text { Total No. of Male } \\
\text { Patient }\end{array}$ & $\begin{array}{c}\text { Total No. Female } \\
\text { Patient }\end{array}$ & $\begin{array}{c}\text { D-Dimer Positive Male } \\
\text { Patient (\%) }\end{array}$ & $\begin{array}{c}\text { D-Dimer Positive Female } \\
\text { Patient (\%) }\end{array}$ & $\begin{array}{c}\text { D-Dimer Negative Male } \\
\text { Patient (\%) }\end{array}$ & $\begin{array}{c}\text { D-Dimer Negative Female } \\
\text { Patient (\%) }\end{array}$ \\
\hline 17 & 10 & 7 & $04(40 \%)$ & $02(28.6 \%)$ & $06(60 \%)$ \\
\hline
\end{tabular}

Table 1B: Biological Reference Interval of D-dimer <0.50ug/L (Age Group: 15-24 Years).

\begin{tabular}{|c|c|c|c|c|c|c|}
\hline Total No. of & Total No. of Male & Total No. Female & D-Dimer Positive Male & D-Dimer Positive Female & D-Dimer Negative Male & D-Dimer Negative
\end{tabular}

\begin{tabular}{c|c|c|c|c|c|}
\hline Sample & Patient & Patient & Patient (\%) & Patient (\%) & Patient (\%) \\
\hline 71 & 32 & 39 & $07(21.9 \%)$ & $06(15.3 \%)$ & $25(78.1 \%)$
\end{tabular}

Table 1C: Biological Reference Interval of D-dimer <0.50ug/L (Age Group: 25-54 Years).

\begin{tabular}{l|l|l|l|l|l|} 
Total No. of & Total No. of Male & Total No. Female & D-Dimer Positive Male & D-Dimer Positive Female & D-Dimer Negative Male \\
\hline D-Dimer Negative Female
\end{tabular}

\begin{tabular}{|c|c|c|c|c|c|c|} 
Sample & Patient & $\begin{array}{c}\text { Patient } \\
\text { Patient (\%) }\end{array}$ & $\begin{array}{c}\text { D-Dime } \\
\text { Patient (\%) }\end{array}$ & $\begin{array}{c}\text { Patient (\%) } \\
\text { Patient (\%) }\end{array}$ \\
\hline 875 & 501 & 374 & $205(41.0 \%)$ & $138(37.0 \%)$ & $296(59.0 \%)$ \\
\hline
\end{tabular}

\begin{tabular}{|l|l|l|l|l|l|l|}
\hline 875 & 501 & 374 & $205(41.0 \%)$ & $138(37.0 \%)$ & $296(59.0 \%)$ & $236(63.0 \%)$ \\
\hline
\end{tabular}

Table 1D: Biological Reference Interval of D-dimer <0.50ug/L (Age Group: 55 Years or above).

\begin{tabular}{|c|c|c|c|c|c|c|}
\hline Total No. of & Total No. of Male & Total No. Female & D-Dimer Positive Male & D-Dimer Positive Female & D-Dimer Negative Male & D-Dimer Negative Female
\end{tabular}

\begin{tabular}{c|c|c|c|c|c|c|c|}
\hline Sample & Patient & Patient & Patient (\%) & Patient (\%) & Patient (\%) \\
\hline 585 & 375 & 210 & $254(67.8 \%)$ & $170(81.0 \%)$ & $121(32.2 \%)$ & $40(19.0 \%)$
\end{tabular}

Table 2A: Biological Reference Interval of IL-6 <6.4pg/ml (Age Group: 0-14 Years).
\begin{tabular}{|c|c|c|c|c|c|c|}
\hline $\begin{array}{c}\text { Total No. of } \\
\text { Sample }\end{array}$ & $\begin{array}{c}\text { Total No. of Male } \\
\text { Patient }\end{array}$ & $\begin{array}{c}\text { Total No. Female } \\
\text { Patient }\end{array}$ & $\begin{array}{c}\text { II-6 Positive Male } \\
\text { Patient (\%) }\end{array}$ & $\begin{array}{c}\text { II-6 Positive Female } \\
\text { Patient (\%) }\end{array}$ & $\begin{array}{c}\text { II-6 Negative Male } \\
\text { Patient (\%) }\end{array}$ & $\begin{array}{c}\text { II-6 Negative Female } \\
\text { Patient (\%) }\end{array}$ \\
\hline 2 & 2 & 0 & $02(100 \%)$ & $00(00 \%)$ & 0 \\
\hline
\end{tabular}

Table 2B: Biological Reference Interval of IL-6 <6.4pg/ml (Age Group: 15-24 Years).

\begin{tabular}{|c|c|c|c|c|c|c|}
\hline $\begin{array}{c}\text { Total No. of } \\
\text { Sample }\end{array}$ & $\begin{array}{c}\text { Total No. of Male } \\
\text { Patient }\end{array}$ & $\begin{array}{c}\text { Total No. Female } \\
\text { Patient }\end{array}$ & $\begin{array}{c}\text { II-6 Positive Male } \\
\text { Patient (\%) }\end{array}$ & $\begin{array}{c}\text { II-6 Positive Female } \\
\text { Patient (\%) }\end{array}$ & $\begin{array}{c}\text { Il-6 Negative Male } \\
\text { Patient (\%) }\end{array}$ & $\begin{array}{c}\text { II-6 Negative Female } \\
\text { Patient (\%) }\end{array}$ \\
\hline 10 & 3 & 7 & $02(66.7 \%)$ & $06(85.8 \%)$ & $01(33.3 \%)$ \\
\hline
\end{tabular}

Table 2C: Biological Reference Interval of IL-6 <6.4pg/ml (Age Group: 25-54 Years).

\begin{tabular}{|c|c|c|c|c|c|c|}
\hline $\begin{array}{c}\text { Total No. of } \\
\text { Sample }\end{array}$ & $\begin{array}{c}\text { Total No. of Male } \\
\text { Patient }\end{array}$ & $\begin{array}{c}\text { Total No. Female } \\
\text { Patient }\end{array}$ & $\begin{array}{c}\text { II-6 Positive Male } \\
\text { Patient (\%) }\end{array}$ & $\begin{array}{c}\text { II-6 Positive Female } \\
\text { Patient (\%) }\end{array}$ & $\begin{array}{c}\text { Il-6 Negative Male } \\
\text { Patient (\%) }\end{array}$ & $\begin{array}{c}\text { II-6 Negative Female } \\
\text { Patient (\%) }\end{array}$ \\
\hline 102 & 61 & 41 & $53(86.9 \%)$ & $34(83.0 \%)$ & $08(13.1 \%)$ & $07(17.0 \%)$ \\
\hline
\end{tabular}

Table 2D: Biological Reference Interval of IL- $6<6.4 \mathrm{pg} / \mathrm{ml}$ (Age Group: 55 Years or Above).

\begin{tabular}{|c|c|c|c|c|c|c|}
\hline $\begin{array}{c}\text { Total No. of } \\
\text { Sample }\end{array}$ & $\begin{array}{c}\text { Total No. of Male } \\
\text { Patient }\end{array}$ & $\begin{array}{c}\text { Total No. Female } \\
\text { Patient }\end{array}$ & $\begin{array}{c}\text { II-6 Positive Male } \\
\text { Patient (\%) }\end{array}$ & $\begin{array}{c}\text { II-6 Positive Female } \\
\text { Patient (\%) }\end{array}$ & $\begin{array}{c}\text { Il-6 Negative Male } \\
\text { Patient (\%) }\end{array}$ & $\begin{array}{c}\text { II-6 Negative Female } \\
\text { Patient (\%) }\end{array}$ \\
\hline 79 & 58 & 21 & $51(87.9 \%)$ & $18(85.8 \%)$ & $07(12.1 \%)$ \\
\hline
\end{tabular}


laboratory in Kolkata, West Bengal, India.

\section{Results}

\section{Category-I: D-Dimer test result analysis} 1D).

Biological Reference Interval of D-dimer $<0.50 \mathrm{ug} / \mathrm{L}$ (Table 1A-

\section{Category-II: Interleukin-6 test result analysis}

Biological Reference Interval of IL-6 $<6.4 \mathrm{pg} / \mathrm{ml}$ (Table 2A-2D).

\section{Conclusions}

The COVID-19 pandemic has put medical knowledge to the challenge of finding treatment for a pathogen whose behaviour is yet to be defined. Evaluation of the results from studies on critically ill COVID-19 patients has led us to conclude that inflammatory hyperresponsiveness leading to cytokine storm is the primary pathogenic event behind increased risk and mortality in hospitalized patients. The pathogenic events manifest as deranged laboratory parameters, including D-dimers and IL-6.

D-dimer is commonly elevated in patients with COVID-19. D-dimer levels correlate with disease severity and are a reliable prognostic marker for mortality in patients affected of COVID- 19 .

The important role of IL- 6 in host defense should always be considered in medical practice. The responses of the treatment for cytokine storm, especially IL-6 production, are still unknown. Elevated systemic IL-6 levels according to COVID-19 severity should be important for determination of higher risk of disease deterioration.

\section{References}

1. Dempfle CE. Validation, calibration, and specificity of quantitative D-dimer assays. Semin Vasc Med. 2005; 5: 315-320.

2. Mosesson MW. On behalf of the Subcommittee on Fibrinogen of the Scientific and Standardization Committee of the ISTH. Terminology for macromolecular derivatives of crosslinked fibrin. Thromb Haemost. 1995; 73: 725-726.

3. Bockenstedt P. D-dimer in venous thromboembolism. N Engl J Med. 2003; 349: 1203-1204.
4. DI Nisio M, Squizzato A, Rutjes AW, Büller HR, Zwinderman AH, Bossuyt PM Diagnostic accuracy of $D$-dimer test for exclusion of venous thromboembolism: a systematic review. J Thromb Haemost. 2007; 5: 296-304.

5. Righini M, Perrier A, De Moerloose P, Bounameaux H. D-Dimer for venous thromboembolism diagnosis: 20 years later. J Thromb Haemost. 2008; 6: 1059-1071.

6. Ten Cate-Hoek AJ, Prins MH. Management studies using a combination of D-dimer test result and clinical probability to rule out venous thromboembolism: a systematic review. J Thromb Haemost. 2005; 3: 2465-2470.

7. Carrier M, Righini M, Djurabi RK, Huisman MV, Perrier A, Wells PS, et al. Vidas D-dimer in combination with clinical pre-test probability to rule out pulmonary embolism. A systematic review of management outcome studies. Thromb Haemost. 2009; 101: 886-892.

8. Goodacre S, Sampson F, Stevenson M, Wailoo A, Sutton A, Thomas S, et al. Measurement of the clinical and cost-effectiveness of non-invasive diagnostic testing strategies for deep vein thrombosis. Health Technol Assess. 2006; 10: 1-168.

9. Righini M, Nendaz M, Le Gal G, Bounameaux H, Perrier A. Influence of age on the cost-effectiveness of diagnostic strategies for suspected pulmonary embolism. J Thromb Haemost. 2007; 5: 1869-1877.

10. Bruinstroop E, Van De Ree MA, Huisman MV. The use of D-dimer in specific clinical conditions: a narrative review. Eur J Intern Med. 2009; 20: 441-446.

11. Houdijk W. Proper observation of patient-related factors is an important determinant in the use of the d-dimer test for exclusion of venous thromboembolism in the ED. American Journal of emergency Medicine. 2007; 25: 255-256.

12. Bakhtiari K, Meijers JC, De Jonge E, Levi M. Prospective validation of the International Society of Thrombosis and Haemostasis scoring system for disseminated intravascular coagulation. Crit Care Med. 2004; 32: 2416-2421.

13. Ferguson-Smith AC, Chen YF, Newman MS, May LT, Sehgal PB, Ruddle $\mathrm{FH}$. "Regional localization of the interferon-beta 2/B-cell stimulatory factor 2/hepatocyte stimulating factor gene to human chromosome 7p15-p21". Genomics. 1988; 2: 203-208.

14. "Raised troponin and interleukin-6 levels are associated with a poor prognosis in COVID-19". Cardiac Rhythm News. 2020.

15. Sakka M, Connors JM, Hekimian G, Martin-Toutain I, et al. Association between D-Dimer levels and mortality in patients with coronavirus disease 2019 (COVID-19): a systematic review and pooled analysis. Journal de Medicine Vasculaire. 2020; 45: 268-274. 